\title{
ASTHMA
}

\section{Cysteinyl leukotrienes and 8-isoprostane in exhaled breath condensate of children with asthma exacerbations}

\author{
E Baraldi, S Carraro, R Alinovi, A Pesci, L Ghiro, A Bodini, G Piacentini, F Zacchello, \\ S Zanconato
}

Thorax 2003;58:505-509

See end of article for authors' affiliations

.....................

Correspondence to: Dr Eugenio Baraldi

Department of Pediatrics,

Via Giustiniani 3, 35128

Padova, Italy;

eugi@pediatria.unipd.it

Accepted for publication 19 February 2003

\begin{abstract}
Background: Cysteinyl leukotrienes (Cys-LTs) and isoprostanes are inflammatory metabolites derived from arachidonic acid whose levels are increased in the airways of asthmatic patients. Isoprostanes are relatively stable and specific for lipid peroxidation, which makes them potentially reliable biomarkers for oxidative stress. A study was undertaken to evaluate the effect of a course of oral steroids on Cys-LT and 8-isoprostane levels in exhaled breath condensate of children with an asthma exacerbation.

Methods: Exhaled breath condensate was collected and fractional exhaled nitric oxide $\left(\mathrm{FE}_{\mathrm{NO}}\right)$ and spirometric parameters were measured before and after a 5 day course of oral prednisone $(1 \mathrm{mg} / \mathrm{kg} /$ day) in 15 asthmatic children with an asthma exacerbation. Cys-LT and 8-isoprostane concentrations were measured using an enzyme immunoassay. $\mathrm{FE}_{\mathrm{NO}}$ was measured using a chemiluminescence analyser. Exhaled breath condensate was also collected from 10 healthy children.

Results: Before prednisone treatment both Cys-LT and 8-isoprostane concentrations were higher in asthmatic subjects (Cys-LTs, $12.7 \mathrm{pg} / \mathrm{ml}$ (IQR 5.4-15.6); 8-isoprostane, $12.0 \mathrm{pg} / \mathrm{ml}(9.4-29.5)$ ) than in healthy children (Cys-LTs, $4.3 \mathrm{pg} / \mathrm{ml}$ (2.0-5.7), $p=0.002 ; 8$-isoprostane, $2.6 \mathrm{pg} / \mathrm{ml}(2.1-3.0)$, $\mathrm{p}<0.001)$. After prednisone treatment there was a significant decrease in both Cys-LT $15.2 \mathrm{pg} / \mathrm{ml}$ $(3.9-8.8), p=0.005)$ and 8 -isoprostane $(8.4 \mathrm{pg} / \mathrm{ml}(5.4-11.6), p=0.04)$ concentrations, but 8 -isoprostane levels remained higher than in controls $(p<0.001)$. $\mathrm{FE}_{\mathrm{NO}}$ levels, which fell significantly after prednisone treatment $(p<0.001)$, did not correlate significantly with either Cys-LT or 8-isoprostane concentrations.

Conclusion: After a 5 day course of oral prednisone there is a reduction in Cys-LT and 8-isoprostane levels in EBC of children with an asthma exacerbation, although 8-isoprostane levels remain higher than in controls. This finding suggests that corticosteroids may not be fully effective in reducing oxidative stress in children with an exacerbation of asthma.
\end{abstract}

A sthma is a condition in which chronic airway inflammation and oxidative stress is involved. There has recently been increasing interest in the use of exhaled breath as a simple non-invasive means for sampling the lower respiratory tract in humans. A number of inflammatory markers found in exhaled breath condensate (EBC) have been investigated as possible biomarkers of disease activity. ${ }^{12}$

$\mathrm{F}_{2}$-isoprostanes are considered markers of oxidative stress, ${ }^{3}$ which seems to be involved in the pathophysiology of asthma. ${ }^{4}$ They are synthesised from arachidonic acid by free radical catalysed lipid peroxidation; their synthesis is mainly independent of cyclooxygenase (COX) action. Among the $\mathrm{F}_{2}$-isoprostanes, 8-isoprostane is the most extensively studied. Increased 8-isoprostane levels have been detected in plasma, urine, ${ }^{6}$ and bronchoalveolar lavage (BAL) fluid ${ }^{6}$ of asthmatic patients. Montuschi et $a l^{7}$ recently found raised levels of 8-isoprostane in the EBC of asthmatic patients, with higher values in those with more severe asthma.

Leukotrienes are mediators generated from arachidonic acid metabolism by the 5-lipoxygenase (5-LO) pathway. Cysteinyl leukotrienes (Cys-LTs), which are the main leukotrienes recovered in the BAL fluid of asthmatic patients, ${ }^{89}$ are synthetised primarily by eosinophils. ${ }^{10}$ Their production is upregulated in asthma and their levels further increase during spontaneous asthma exacerbations, allergen challenge, ${ }^{11}$ and exercise induced bronchoconstriction. ${ }^{10}$ Cys-LTs have many effects that are important in the pathophysiology of asthma and may contribute to airway remodelling in chronic asthma. ${ }^{10}$ High levels of Cys-LTs have also been found in the EBC of adults and children with persistent asthma, despite corticosteroid treatment. ${ }^{12}$
To date, only one preliminary study ${ }^{14}$ has shown raised 8-isoprostane levels in the EBC of asthmatic children, and there are no data on eicosanoid levels measured during asthma exacerbations or on the effect of oral steroid treatment.

The aim of this study was to assess the effect of a course of oral glucocorticoids on the Cys-LT and 8-isoprostane levels detected in the EBC of children with acute asthma. The concentration of these markers was measured before and after 5 days of treatment with oral prednisone in children with an asthma exacerbation.

\section{METHODS}

\section{Study subjects}

Fifteen asthmatic children (10 boys) with an acute asthma exacerbation were included in the study (table 1). All were atopic and were sensitised to common allergens (Dermatophagoides pteronyssinus, D farinae, mixed grass pollen, Artemisia vulgaris, Alternaria, dog, and cat) as evaluated by skin prick tests and/or RAST. They were recruited from patients attending the Pulmonology/Allergy outpatients clinic at the Pediatric Department of Padova. The diagnosis of asthma was based on clinical history and examination, pulmonary function parameters, and the pulmonary function response to $\beta_{2}$ adrenergic agents according to international guidelines. ${ }^{15}$ Eleven children with mild or moderate persistent asthma were on maintenance therapy with low to medium doses of inhaled corticosteroids (budesonide by Turbohaler and fluticasone by MDI and spacer) at a constant dose for at least 2 months. Four patients with intermittent asthma were not taking any regular medication. An asthma exacerbation was defined as 
Table 1 Subject characteristics, pulmonary function data (\% predicted), exhaled $\mathrm{NO}\left(\mathrm{FE}_{\mathrm{NO}}\right)$ concentrations, and exhaled breath condensate (EBC) volumes

\begin{tabular}{|c|c|c|c|}
\hline & \multicolumn{2}{|l|}{ Asthma $(n=15)$} & \multirow[t]{2}{*}{ Controls $(n=10)$} \\
\hline & $\begin{array}{l}\text { Acute exacerbation } \\
\text { (T1) }\end{array}$ & $\begin{array}{l}\text { After } 5 \text { days prednisone } \\
\text { (T2) }\end{array}$ & \\
\hline Mean age (years) & 11.0 (range 6-16) & & 10.1 (range 4-14) \\
\hline Atopy & 15 & & None \\
\hline $\mathrm{FEV}_{1}(\% \text { pred })^{* *}$ & $59(55-89)$ & $91(75-105) \dagger$ & $96(92-98) \dagger^{*}$ \\
\hline $\mathrm{FE}_{\mathrm{NO}}(\mathrm{ppb})^{* *}$ & $34.7(16.9-77.6)$ & $16.9(11.0-39.1) \dagger$ & \\
\hline $\mathrm{EBC}$ volume $(\mathrm{ml})$ ** & $1.5(1.2-1.7)$ & $1.4(0.8-1.6) \ddagger$ & $1.5(1.3-1.5) \neq^{*}$ \\
\hline
\end{tabular}

increasing signs and symptoms of asthma (coughing, wheezing, shortness of breath) unresponsive to the patient's routine asthma medication and additional $\beta_{2}$ agonist therapy. The children were examined by a physician and underwent measurement of fractional exhaled nitric oxide $\left(\mathrm{FE}_{\mathrm{No}}\right)$, spirometric tests, and EBC collection. Oral prednisone treatment ( $1 \mathrm{mg} / \mathrm{kg} / \mathrm{day}$ ) was then started in all patients. After 5 days of treatment the patients were examined again and EBC collection, $\mathrm{FE}_{\mathrm{No}}$ measurement, and spirometric tests were repeated.

Ten healthy white children (six boys) with no history of asthma, atopy, or respiratory infections in the previous 4 weeks also underwent EBC collection and spirometric tests (table 1). None of the control subjects was taking any medication or smoked.

The ethics committee of our hospital reviewed and approved the protocol and all parents gave their informed consent.

\section{Exhaled breath condensate (EBC) collection}

EBC samples were collected in a condensing device composed of two glass chambers (Incofar Srl, Modena, Italy). ${ }^{7}$ The inner glass chamber was cooled with ice and suspended in a larger glass chamber. The children, with no nose clip, were instructed to breathe tidally through their mouths via a two way non-rebreathing valve for 15 minutes. To minimise salivary contamination the two way valve served as a saliva trap with a $12 \mathrm{~cm}$ banded tube vertically positioned between the mouthpiece and the condensing device, while the child's mouth remained in a position lower than the inlet of the device. In addition, children were asked to swallow their saliva periodically. The temperature of collection was $0^{\circ} \mathrm{C}$. The collected EBC samples were then immediately stored in sterile tubes at $-70^{\circ} \mathrm{C}$.

Concentrations of 8-isoprostane and Cys-LTs (LTC4/D4/E4) in EBC were measured by specific enzyme immunoassay (EIA) kits (8-isoprostane, Cayman Chemical Milan, Italy; LTC4/D4/E4 Amersham Pharmacia Biotech, Milan, Italy) as described elsewhere. ${ }^{72}$ The method was modified to lower the detection limit (8-isoprostane $1 \mathrm{pg} / \mathrm{ml}$, Cys-LTs $4 \mathrm{pg} / \mathrm{ml}$ ); for those samples below the lowest detection limits the data were expressed as half the detection limit.

To assess the repeatability of Cys-LT and 8-isoprostane measurements, EBC was collected on two different days, 24 hours apart, in 16 subjects for repeated 8-isoprostane measurements and in six subjects for repeated Cys-LT measurements.

\section{Fractional exhaled nitric oxide $\left(\mathrm{FE}_{\mathrm{No}}\right)$ measurement}

$\mathrm{FE}_{\mathrm{No}}$ was measured using the NIOX system (Aerocrine, Stockholm, Sweden) with a single breath online method according to ATS guidelines. ${ }^{16}$ Children inhaled NO-free air and exhaled through a dynamic flow restrictor with a target flow of $50 \mathrm{ml} / \mathrm{s}$ for at least 6-7 seconds.

\section{Pulmonary function tests}

Pulmonary function parameters (forced vital capacity (FVC), forced expiratory volume in 1 second $\left(\mathrm{FEV}_{1}\right)$, mid forced expiratory flow $\left(\mathrm{FEF}_{25-75}\right)$ ) were measured by means of a 10 litre bell spirometer (Biomedin, Padova, Italy). $\beta_{2}$ agonists were suspended 3 hours before the procedure.

\section{Statistical analysis}

Data are expressed as median and interquartile range (IQR). $\mathrm{FE}_{\mathrm{NO}}, 8$-isoprostane, Cys-LT levels, and spirometric parameters before and after prednisone treatment were compared by Wilcoxon's signed rank test. Differences between asthmatic and control groups were analysed using the Mann-Whitney test. Correlations were evaluated by Spearman's rank test. The repeatability of Cys-LT and 8-isoprostane concentrations in EBC was assessed using the method of Bland and Altman. ${ }^{17}$ The results were considered significant at a value of $\mathrm{p}<0.05$.

\section{RESULTS}

In children with an asthma exacerbation both Cys-LT and 8-isoprostane levels in EBC were higher than in healthy children (Cys-LTs: asthmatics, $12.7 \mathrm{pg} / \mathrm{ml}$ (IQR 5.4-15.6), controls, $4.3 \mathrm{pg} / \mathrm{ml}(2.0-5.7), \mathrm{p}=0.002 ; 8$-isoprostane: asthmatics, $12.0 \mathrm{pg} / \mathrm{ml}$ (9.4-29.5), controls, $2.6 \mathrm{pg} / \mathrm{ml}(2.1-3.0), \mathrm{p}<0.001)$.

After 5 days of treatment with oral prednisone both Cys-LT and 8-isoprostane concentrations in the EBC decreased significantly in asthmatic patients (Cys-LTs, $5.2 \mathrm{pg} / \mathrm{ml}$ (IQR 3.9-8.8), $\mathrm{p}=0.005$, fig $\mathrm{l} ; 8$-isoprostane, $8.4 \mathrm{pg} / \mathrm{ml}$ (5.4-11.6), $\mathrm{p}=0.04$, fig 2 ), but 8 -isoprostane levels remained higher than in healthy subjects $(\mathrm{p}<0.001)$. The median difference between measurements made before and after prednisone treatment was $-6 \mathrm{pg} / \mathrm{ml}$ (IQR -9.8 to -0.5 ) for Cys-LTs and $-4.9 \mathrm{pg} / \mathrm{ml}$ (IQR -21.1 to +1.1$)$ for 8 -isoprostane. The percentage reductions in both Cys-LT and 8-isoprostane after prednisone correlated significantly with baseline Cys-LT and 8-isoprostane levels (Cys-LTs: $r=0.58, \mathrm{p}=0.02 ; 8$-isoprostane: $r=0.77$, $\mathrm{p}<0.001$ ).

Before prednisone treatment there was a significant correlation between EBC 8-isoprostane and Cys-LT levels in asthmatic children $(r=0.62, \mathrm{p}=0.01)$ but no significant correlation was seen after steroid treatment $(r=-0.14 ; \mathrm{p}=0.63)$.

After prednisone treatment there was a significant decrease in $\mathrm{FE}_{\mathrm{NO}}$ levels $(\mathrm{p}<0.001)$ and a significant improvement in spirometric parameters (table 1). $\mathrm{FE}_{\mathrm{No}}$ levels measured before and after prednisone treatment did not correlate significantly with either 8-isoprostane (before: $r=0.15, \mathrm{p}=0.06$; after: $r=0.10, \mathrm{p}=0.72$ ) or Cys-LT (before: $r=0.40, \mathrm{p}=0.14$; after: $r=0.48, \mathrm{p}=0.07$ ) levels. No significant correlation was found between spirometric parameters and $\mathrm{FE}_{\mathrm{No}}$ Cys-LT, or 8-isoprostane levels before or after corticosteroid treatment.

There were no significant differences in EBC volumes between the different groups ( $1.5 \mathrm{ml}$ (IQR $1.2-1.7$ ) in asthmatic children before treatment, $1.4 \mathrm{ml}(0.8-1.6)$ in asthmatic children after treatment, and $1.5 \mathrm{ml} \mathrm{(1.3-1.5)}$ in controls). 


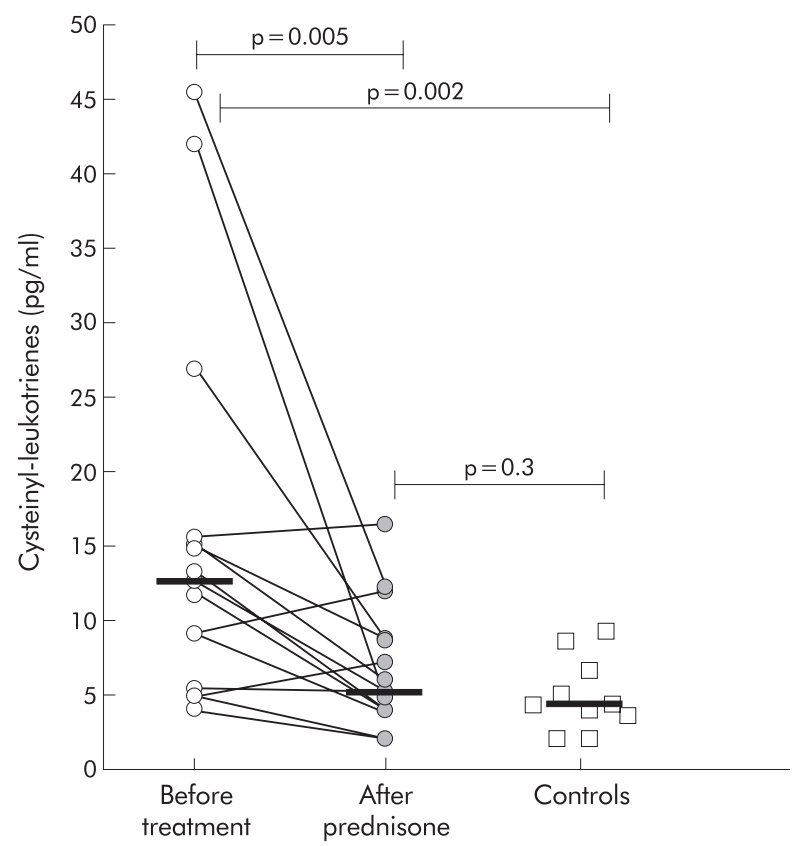

Figure 1 Exhaled breath condensate concentrations of Cys-LT in healthy controls and children with acute asthma before and after 5 days of treatment with prednisone. Individual and median values are shown.

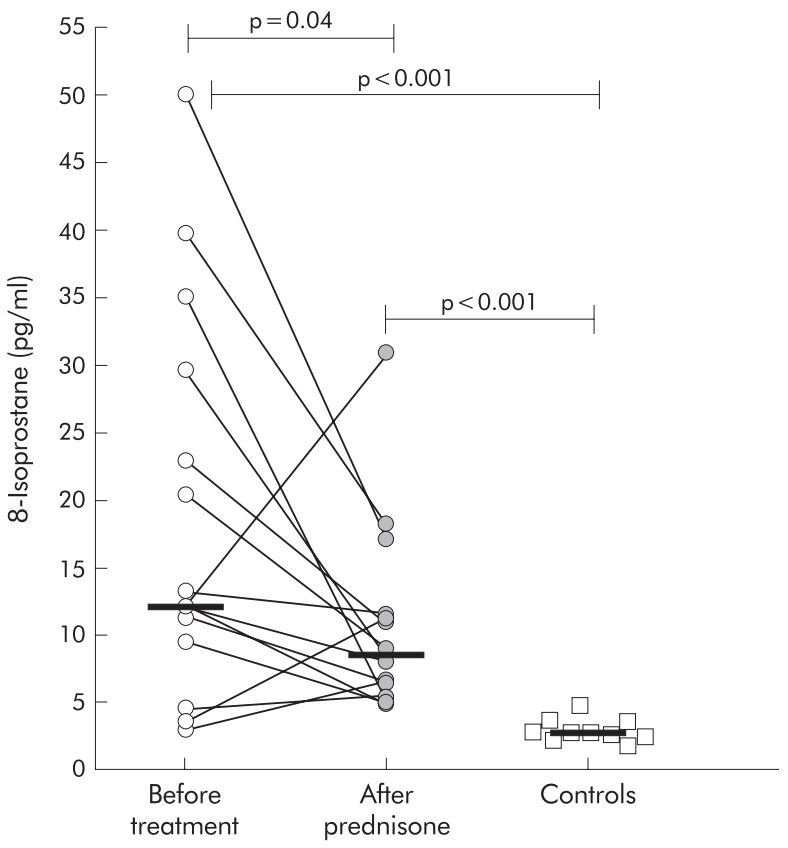

Figure 2 Exhaled breath condensate concentrations of 8-isoprostane in healthy controls and children with acute asthma before and after 5 days of treatment with prednisone. Individual and median values are shown.

The coefficient of repeatability ${ }^{17}$ was $3.2 \mathrm{pg} / \mathrm{ml}$ for 8 -isoprostane with 15 of 16 values lying within this range. For Cys-LTs the coefficient of repeatability was $3.2 \mathrm{pg} / \mathrm{ml}$ and all the values were within this range. In neither plot was there an increase in the spread of differences with increasing mean, which suggests good repeatability for both compounds.

\section{DISCUSSION}

This study shows that children with an asthma exacerbation have higher Cys-LT and 8-isoprostane concentrations in EBC than healthy controls. Moreover, both Cys-LT and 8-isoprostane concentrations in EBC were found to decrease after a 5 day course of oral prednisone. The decrease in 8 -isoprostane was smaller, however, and its levels after corticosteroid treatment were still higher in asthmatic children than in healthy subjects. To our knowledge, no other study has assessed the EBC levels of eicosanoids during an asthma exacerbation and the effects of oral corticosteroids.

Cys-LTs are lipid mediators which are not simply bronchoconstrictors but also have a role in the pathophysiology of asthma. ${ }^{10}$ They increase vascular permeability, mucus production, and airway responsiveness, and may contribute to modulating chronic eosinophilic inflammation. ${ }^{10}$ The higher levels of Cys-LTs found in the airways of asthmatic patients are consistent with the results of previous studies. Increased LTC4 levels were reported in BAL fluid from atopic subjects with mild asthma ${ }^{8}$ and from asthmatic patients after allergen challenge. ' Induced sputum Cys-LT levels were higher in asthmatic patients than in controls and were raised in patients studied within 48 hours of an acute exacerbation of asthma ${ }^{18}$ and within 24 hours of allergen challenge. ${ }^{11}$ Raised Cys-LT levels were also recently found in the EBC of adults and children with asthma. ${ }^{12}{ }^{13}$

Conflicting data have been reported on the effects of corticosteroids on Cys-LTs in vitro and in vivo. In vitro, corticosteroids are thought to reduce the production of Cys-LTs by inducing lipocortin binding of phospholipids, preventing access to phospholipase $\mathrm{A}_{2}{ }^{19}$ In our study a 5 day course of oral corticosteroid treatment reduced Cys-LT levels in vivo. This reduction was greater in patients with higher baseline Cys-LT levels (fig 1), and the relationship between Cys-LT reduction and baseline values was lost when the three patients with the highest values were excluded from the statistical analysis. Earlier studies found no effect of corticosteroids on BAL fluid levels of Cys-LTs in vivo. Dworski et al ${ }^{20}$ found that a 6-9 day course of oral prednisolone had no effect on Cys-LTs in BAL fluid from asthmatic patients. In addition, Hood et $a l^{21}$ showed that systemic methylprednisolone can reduce LTC4 synthesis in blood granulocytes and mononuclear cells but not in BAL fluid cells of asthmatic patients. Both studies included subjects with stable asthma, however, while our patients were studied during an asthma exacerbation.

It has been shown that Cys-LT levels undergo a further increase during an asthma exacerbation in subjects with asthma. ${ }^{182}$ It may be that in vivo corticosteroids can selectively affect the increased LT production characteristic of acute exacerbations. In agreement with this hypothesis, Shindo $\mathrm{et}_{\mathrm{al}} \mathrm{l}^{23}$ found that 5 -hydroperoxyeicosatetraenoic acid (5-HPETE) levels, which can be considered a measure of 5-LO activity, were significantly higher in the cytosol of blood eosinophils obtained from asthmatic patients during acute wheezing than in those in remission, and they were inhibited by prednisolone with a dose dependent mechanism. Evidence that prednisolone reduces 5-HPETE suggests that it may lead to a downregulation of 5-LO, also causing a decrease in Cys-LT synthesis in patients with acute wheezing.

The EBC levels of 8-isoprostane were also measured in our study. Isoprostanes are metabolites of arachidonic acid, synthesised mainly by a non-enzymatic pathway catalysed by free radicals. ${ }^{1} 8$-isoprostane is considered a promising marker of oxidative stress and has many favourable characteristics-it is a stable metabolite, specific for lipid peroxidation, synthesised in vivo, and biologically active. ${ }^{3}$ Earlier studies showed higher 8 -isoprostane levels in the plasma, ${ }^{5}$ urine, ${ }^{6}$ BAL fluid, ${ }^{6}$ and $\mathrm{EBC}^{7}$ of asthmatic patients. We found that 8 -isoprostane levels were significantly higher in the EBC of children with an acute asthma exacerbation than in healthy children. Other markers of oxidative stress such as hydrogen peroxide are also increased in the EBC of patients with several inflammatory disorders of the lung, including bronchial asthma and cystic fibrosis. ${ }^{12} 2425$ 
Concentrations of 8-isoprostane fell in our patients after treatment with oral prednisone, though to a lesser extent than Cys-LT levels, and remained significantly higher in asthmatic children than in healthy controls. These results are in keeping with the findings of Montuschi et al who reported that patients with severe asthma treated with oral prednisolone had higher 8-isoprostane levels in their EBC than patients with mild and moderate asthma, suggesting a relative resistance of 8-isoprostane to steroids. Similarly, the only preliminary data available in children show that corticosteroid treated patients with severe asthma had higher 8-isoprostane levels than healthy children. ${ }^{14}$ We found a significant correlation between 8-isoprostane and Cys-LT levels before, but not after, treatment with prednisone, confirming that steroids may affect isoprostanes and leukotrienes differently. Although in our study there was a significant decrease in EBC concentrations of Cys-LT and 8-isoprostane in the whole group of asthmatic subjects after prednisone, three patients showed an increase in Cys-LT and another three an increase in 8-isoprostane levels after treatment. There was no difference in asthma duration, spirometric parameters, $\mathrm{FE}_{\mathrm{No}}$ values, or improvement in $\mathrm{FEV}_{1}$ following treatment between these patients and the rest of the study group.

In a recently reported study Hunt et $a^{26}$ showed that the $\mathrm{pH}$ of condensate is substantially lower in patients with an acute exacerbation of asthma than in healthy subjects and may improve with corticosteroid treatment. It is therefore possible that an acidic microenvironment favours oxidative stress, as suggested by the relationship found between $\mathrm{pH}$ and concentrations of 8-isoprostane and NO metabolism products. ${ }^{27}$

As in previous studies, we found that levels of $\mathrm{FE}_{\mathrm{No}}$, which is considered another marker of airway inflammation, were increased in asthmatic patients and decreased significantly after corticosteroid therapy. $\mathrm{FE}_{\mathrm{NO}}$ values did not correlate with 8 -isoprostane and Cys-LT levels, however. Most of the children were on long term treatment with inhaled corticosteroids at the time of the acute exacerbation. Since corticosteroid treatment may affect $\mathrm{FE}_{\mathrm{No}}$ more than eicosanoid levels, ${ }^{721}$ this probably accounts for the lack of correlation between these exhaled markers. No correlation was found between Cys-LT levels and $\mathrm{FE}_{\mathrm{NO}}$ by Csoma et $a l^{13}$ either in steroid naive or steroid treated children, suggesting that Cys-LTs and $\mathrm{FE}_{\mathrm{No}}$ may reflect different aspects of airway inflammation. Another explanation for the lack of relationship between $\mathrm{FE}_{\mathrm{No}}$ and Cys-LTs may be related to varying concentrations of different leukotrienes in EBC.

EBC collection has only recently been used to analyse volatile and non-volatile substances from the airways of patients with lung diseases, ${ }^{125}$ and there is limited information concerning its use in children. Successful collection of EBC using different devices has been reported, ${ }^{271324} 25$ but no standardised methods have been established and formal recommendations are required to ensure uniformity of measurement. ${ }^{125}$ Our study shows that EBC collection is non-invasive, safe, and feasible in asthmatic children, even in the event of flow limitation. In addition, EBC can be repeated regularly to monitor airway inflammation. A similar study design with repeated measurements of another marker of oxidative stress-hydrogen peroxide- - has been used by Jobsis et $a l^{24}$ in children with cystic fibrosis with moderate to severe airway obstruction (mean FEV $155 \%$ predicted). The concentration of hydrogen peroxide in EBC was measured before and after antibiotic treatment and was found to be a helpful marker for monitoring oxidative stress in these patients. ${ }^{24}$ However, for a better understanding of the clinical relevance of these new assays, further studies are necessary involving a specific time course of biomarkers measured in EBC and using other methods of assessing airway inflammation and biochemistry ( $\mathrm{FE}_{\mathrm{NO}}$, BAL, induced sputum, and bronchial biopsy).

In conclusion, children with an exacerbation of asthma have higher EBC concentrations of Cys-LTs and 8-isoprostane than healthy controls. The concentrations of these lipid mediators fell significantly after a 5 day course of treatment with oral prednisone, although 8-isoprostane levels remained higher than in healthy children. These findings suggest that a short course of oral corticosteroid therapy may not be fully effective in reducing oxidative stress in children with an asthma exacerbation. Moreover, our study confirms that EBC is a useful non-invasive tool for assessing airway inflammation in asthmatic children, even during an acute exacerbation.

\section{ACKNOWLEDGEMENT}

The authors acknowledge the help of Dr Massimo Corradi.

\section{Authors' affiliations}

E Baraldi, S Carraro, L Ghiro, F Zacchello, S Zanconato, Department of Pediatrics, University of Padova, Italy

A Bodini, G Piacentini, Department of Pediatrics, University of Verona, Italy

R Alinovi, A Pesci, Department of Clinical Medicine, Nephrology and Health Sciences, University of Parma, Italy

\section{REFERENCES}

1 Kharitonov SA, Barnes PJ. Exhaled markers of pulmonary disease. Am J Respir Crit Care Med 2001;163:1693-722.

2 Mutlu JM, Garey KW, Robbins RA, et al. Collection and analysis of exhaled breath condensate in humans. Am J Respir Crit Care Med $2001 \cdot 164: 731-7$

3 Janssen LJ. Isoprostanes: an overview and putative roles in pulmonary pathophysiology. Am J Physiol Lung Cell Mol Physiol 2001;280:L106782

4 Dworski R. Oxidant stress in asthma. Thorax 2000;55(Suppl 2):S51-3.

5 Wood LG, Fitzgerald DA, Gibson PG, et al. Lipid peroxidation as determined by plasma isoprostanes is related to disease severity in mild asthma. Lipids 2000;35:967-74

6 Dworski R, Murray JJ, Jackson Roberts II L, et al. Allergen-induced synthesis of $\mathrm{F}_{2}$-isoprostane in atopic asthmatics. Am J Respir Crit Care Med 1999:160:1947-51

7 Montuschi P, Corradi M, Ciabattoni G, et al. Increased 8-isoprostane, a marker of oxidative stress, in exhaled air condensate of asthma patients. Am J Respir Crit Care Med 1999;160:216-20.

8 Wardlaw AJ, Hay H, Cromwell O, et al. Leukotrienes, $\mathrm{LTC}_{4}$ and $\mathrm{LTB}_{4}$, in bronchoalveolar lavage in bronchial asthma and other respiratory diseases. J Allergy Clin Immunol 1989;84:19-26.

9 Wenzel SE, Larsen GL, Johnston K, et al. Elevated levels of leukotriene $\mathrm{C}_{4}$ in bronchoalveolar lavage fluid from atopic asthmatics after endobronchial allergen challenge. Am Rev Respir Dis 1990;142:112-9.

10 Bisgaard $\mathbf{H}$. Leukotriene modifiers in pediatric asthma management. Pediatrics 2001;107:381-90.

11 MacFarlane AJ, Dworski R, Sheller JR, et al. Sputum cysteinyl leukotrienes increase 24 hours after allergen inhalation in atopic asthmatics. Am J Respir Crit Care Med 2000;161:1553-8.

12 Hanazawa T, Kharitonov SA, Barnes PJ. Increased nitrotyrosine in exhaled breath condensate of patients with asthma. Am J Respir Crit Care Med 2000;162:1273-6.

13 Csoma Z, Kharitonov SA, Balint B, et al. Increased leukotrienes in exhaled breath condensate in childhood asthma. Am J Respir Crit Care Med 2002:166:1345-9.

14 Shahid SK, Kharitonov SA, Csoma SZ, et al. Exhaled 8-isoprostane as a marker of airway inflammation in asthmatic children. Eur Respir $J$ 2001; 18(suppl 33):39s.

15 National Asthma Education and Prevention Program. Expert panel report 2: guidelines for the diagnosis and management of asthma. $\mathrm{NIH}$ Publication 97-4051. Bethesda, MD: National Heart, Lung, and Blood Institute, 1997.

16 American Thoracic Society. Recommendations for online and offline measurement of exhaled nitric oxide and nasal nitric oxide in children. Am J Respir Crit Care Med 1999;160:2104-17.

17 Bland JM, Altman DG. Statistical methods for assessing agreement between two methods of clinical measurement. Lancet 1986;i:307-10

18 Pavord ID, Ward R, Woltmann G, et al. Induced sputum eicosanoid concentration in asthma. Am J Respir Crit Care Med 1999;160:1905-9.

19 Crocker IC, Yi Zhou C, Bewtra AK, et al. Glucocorticosteroids inhibit leukotriene production. Ann Allergy Asthma Immunol 1997;78:497-505.

20 Dworski R, Fitzgerald GA, Oates JA, et al. Effect of oral prednisone on airway inflammatory mediators in atopic asthma. Am J Respir Crit Care Med 1994;149:953-9

21 Hood PP, Cotter TP, Costello JF, et al. Effect of intravenous corticosteroid on ex vivo leukotriene generation by blood leucocytes of normal and asthmatic patients. Thorax 1999;54:1075-82.

22 Oosaky R, Mizushima Y, Kawasaki A, et al. Urinary excretion of leukotriene $E_{4}$ and 11 -dehydrothromboxane $B_{2}$ in patients with spontaneous asthma attacks. Int Arch Immunol 1997;1 14:373-8. 
23 Shindo K, Machida M, Fukumura $M$ et al. Prednisolone inhibits synthesis of 5 -H(P)ETE in eosinophils from asthmatic patients during a wheezing attack but not during remission. Prostaglandins Leukot Essent Fatty Acids 1998;58:1 11 1-7.

24 Jobsis Q, Raatgeep HC, Schellekens SL, et al. Hydrogen peroxide and nitric oxide in exhaled air of children with cystic fibrosis during antibiotic treatment. Eur Respir J 2000;16:95-100.
25 Hunt J. Exhaled breath condensate: an evolving tool for noninvasive evaluation of lung disease. J Allergy Clin Immunol 2002;1 10:28-34.

26 Hunt J, Fang K, Malik R, et al. Endogenous airway acidification. Am J Respir Crit Care Med 2000;161:694-9.

27 Kostikas K, Papatheodorou G, Ganas K, et al. pH in expired breath condensate of patients with inflammatory airway diseases. Am J Respir Crit Care Med 2002; 165:1364-70.

\section{LUNG ALERT}

Treatment of concurrent OSA may benefit patients with heart failure

$\Delta$ Kaneko Y, Floras JS, Usui K, et al. Cardiovascular effects of continuous positive airway pressure in patients with heart failure and obstructive sleep apnea. N Engl J Med 2003;348:1233-41

n obstructive sleep apnoea (OSA), recurrent episodes of transient asphyxia or increased effort of breathing against a partially obstructed glottis have been shown to increase the sympathomimetic outflow. There is a consequent absence of the customary reduction in systemic blood pressure and heart rate during sleep and an elevation of daytime systolic blood pressure, possibly contributing to progression of heart failure. The prevalence of sleep disordered breathing among patients with heart failure is of the order of $11-37 \%$, and treatment of this condition with continuous positive airway pressure (CPAP) is likely to improve cardiovascular function and consequently reduce morbidity and mortality.

In this Canadian study 24 middle aged patients with optimally (pharmacologically) managed heart failure (left ventricular ejection fraction (LVEF) $<48 \%$ by echocardiography) and asymptomatic OSA (Epworth sleepiness scale score $<6 / 24,>20$ apnoea/hypopnoeas per hour; at least $50 \%$ obstructive from polysomnography) were randomly assigned to receive CPAP or to remain on optimal pharmacological treatment (controls). One month later there was evidence of an $8 \%$ increase in LVEF and a $10 \mathrm{~mm} \mathrm{Hg}$ reduction in the daytime systolic blood pressure in the CPAP group while diastolic blood pressure remained unchanged. These changes were significantly different from the control group.

The authors conclude that heart failure patients (ischaemic or non-ischaemic) with sleep disordered breathing (although asymptomatic) may benefit from the adjunctive use of CPAP. The impact of this modest increase in LVEF on patients' symptoms, health related quality of life, and mortality needs to be established in larger multicentre trials and with longer term treatment before it can be recommended to the large population of patients with heart failure

I Chakravorty 